\title{
Efeitos do tamanho da partícula e da forma física da ração sobre o desempenho, rendimento de carcaça e peso dos órgãos digestivos de frangos de corte
}

\author{
[Effects of particle size and physical form of ration on performance, carcass yield and \\ weight of digestive organs of broiler chickens] \\ C.A.A. López, N.C. Baião \\ Escola de Veterinária da UFMG \\ Caixa Postal 567 \\ 30123-970 - Belo Horizonte, MG
}

\begin{abstract}
RESUMO
Compararam-se os efeitos do tamanho da partícula e da forma física da ração sobre o desempenho, rendimento de carcaça e peso dos órgãos digestivos de frangos de corte. Foram utilizados 900 aves (machos) da linhagem Ross-308, de 1 a 47 dias de idade. O delineamento experimental foi inteiramente ao acaso com arranjo fatorial $3 \times 2$ (três formas físicas - farelada, granulada e expandida-granulada - e dois tamanhos de partícula - média e grossa), com cinco repetições de 30 aves. Observou-se efeito de interação entre granulometria e forma física da ração para peso vivo $(\mathrm{P}<0,05)$. Com granulometria média o peso das aves aumentou com o aumento do grau de processamento da ração (expandida-granulada $>$ granulada $>$ farelada). Não foram observadas diferenças entre o peso dos frangos que receberam as rações com granulometria grossa e processadas. Os frangos alimentados com as rações fareladas e granulometria grossa foram significativamente mais leves em relação aos frangos dos outros tratamentos. O consumo de ração não foi influenciado pela granulometria. Observou-se efeito da interação granulometria e forma física da ração para conversão alimentar e viabilidade $(\mathrm{P}<0,05)$. Nas rações com granulometria média a melhor conversão alimentar e a mortalidade mais elevada foram observadas com a ração expandidagranulada. Esse comportamento não foi observado nas rações com granulometria grossa. A forma física e a granulometria das rações não influenciaram o rendimento de carcaça. As rações processadas produziram frangos com menor peso da moela e maior peso do fígado em relação ao peso corporal.
\end{abstract}

Palavras-chave: frango, moagem, granulometria, pelete, expansão

\begin{abstract}
An experiment was carried out to compare the effects of dietary particle size and physical form of the ration on performance and weights of digestive organs of broiler chickens. Nine hundred day-old broiler chicks male of Ross line were used during the 47 days of the trial. The experiment followed a completely randomized $3 \times 2$ factorial design: three physical forms of ration (mash, pellet and expanded-pellet) $x$ two methods of grinding (intermediary and coarse), with five replicates of 30 birds. Significant interaction effect of physical form of the ration and method of grinding on body weight was found $(P<0.05)$. In the intermediary grinding rations, broilers grew faster as processing intensity of ration increased (expandedpellet $>$ pellet $>$ mash). Dietary particle size did not affect feed intake of broilers. Birds fed processed rations had higher feed consumption. Significant interaction effect of the physical form of ration and grinding method on feed conversion and viability $(P<0.05)$ was observed. Within intermediary grinding rations, feed conversion was lower and mortality was higher with the expanded-pellet diet. This pattern did not show up with the coarse grinding rations. The physical form and particle size of rations did not
\end{abstract}

Recebido para publicação em 24 de abril de 2003

Recebido para publicação, após modificações, em 12 de setembro de 2003

E-mail: cesaryol@hotmail.com 
Efeitos do tamanho da partícula...

affect carcass yield (\% body weight). The relative weight (\% body weight) of gizzard was lower and that of liver was higher $(P<0.05)$ with the expanded-pellet and pellet rations.

Keywords: broiler, grinding, particle size, pellet, expansion

\section{INTRODUÇÃO}

A tecnologia da expansão da ração surgida recentemente têm como objetivo principal melhorar a qualidade do pelete. A expansão inclui o condicionamento com vapor, que hidrata e aquece o alimento, e um expander, que produz calor adicional antes da granulação. $\mathrm{O}$ expander segue o mesmo princípio da extrusão seca (Heidenreich, 1999). A intensidade do tratamento térmico determina o grau de modificação do amido (gelatinização), a disponibilidade do conteúdo celular para digestão e absorção e a pasteurização da mistura alimentar (Lucht, 2002). Com a expansão da ração têm sido observadas melhoras na qualidade do pelete e na digestibilidade da gordura e da fibra. As respostas têm sido pouco consistentes sobre o desempenho dos frangos (Rokey, 1995).

A ração peletizada provoca aumento de consumo da ração e evita que o frango selecione as partículas maiores. A temperatura empregada no processo de peletização, se adequadamente controlada, gelatiniza parcialmente o amido, solubiliza as proteínas e facilita a ação e o acesso das enzimas, aumentando a digestibilidade, se a pressão decorrente do processo romper parte da parede celular do alimento. Além disso, permite menor esforço físico das aves e, conseqüentemente, menor gasto energético para consumir ração. Aves alimentadas com ração peletizada apresentam maior propensão à ascite e à síndrome de morte súbita (Capdevila, 1997).

O consumo de alimento e o desempenho de frangos de corte são influenciados pelo tamanho das partículas da ração graças à sua capacidade em selecionar o tamanho adequado da partícula de acordo com a idade (Reece et al., 1986).

Segundo Portella et al.(1988), a escolha do tamanho adequado da partícula não está associada à composição química da ração; os pintos preferem a ração com partículas maiores que $1,18 \mathrm{~mm}$ e, quando mais velhos, maior que $2,36 \mathrm{~mm}$.
Lott et al. (1992) sugeriram que o diâmetro geométrico médio (DGM) de $1,196 \mathrm{~mm}$ é muito grande e pode prejudicar o desempenho das aves jovens. De acordo com Nir et al.(1995), os pintos preferem dietas com partículas de 0,7 a $0,9 \mathrm{~mm}$. Deaton et al. (1995) não encontraram diferenças no desempenho dos frangos alimentados com rações cujas partículas mediam 0,679, 0,987 e $1,289 \mathrm{~mm}$.

O tamanho das partículas do alimento e a forma física da ração influenciam sua velocidade de passagem no trato gastrintestinal (Macari et al., 1994). A velocidade de passagem de partículas maiores é mais lenta do que a de partículas menores, e a das dietas peletizadas mais rápida do que a das fareladas (Nir et al., 1994). O menor tamanho das partículas não parece ter efeito negativo sobre o desempenho dos frangos, mesmo após serem transformadas em peletes (Nir et al., 1995).

De acordo com Nir (1998), o alto consumo de dietas granuladas provoca aumento da necessidade de oxigênio no intestino em função do número reduzido de refeições, da maior carga intestinal, pela maior presença de quimo, e da maior incidência de desordens intestinais subclínicas provocada pelo aumento do $\mathrm{pH}$ da moela. Aparentemente, o alimento farelado resulta em partição mais eficiente do oxigênio, por ser consumido de modo mais regular e permanecer por períodos mais longos na moela em pH mais baixo. Nesse caso, a carga intestinal é mais leve em relação à das rações peletizadas.

Peisker (1994) relatou melhor conversão alimentar e redução na velocidade de crescimento de frangos alimentados com dietas expandidas e granuladas em relação às dietas somente granuladas. Segundo Rokey (1995), a expansão/granulação de dietas à base de milho e soja não oferecem vantagens na alimentação de frangos de corte machos. As mesmas dietas melhoraram o crescimento dos frangos de corte fêmeas. Essa diferença poderia estar ligada à destruição da lisina pelo processamento, uma vez 
que as necessidades desse aminoácido são maiores em frangos machos do que em fêmeas.

Com relação a carcaça, López e Baião (2002) não verificaram diferenças no rendimento de carcaça quando compararam dietas fareladas e granuladas com diferentes granulometrias. Os autores observaram menor peso da moela e do pâncreas nas aves alimentadas com as rações granuladas.

O objetivo deste experimento foi avaliar os efeitos da granulometria (média e grossa) e da forma física da ração (farelada, granulada e expandidada-granulada) sobre o desempenho de frangos de corte, rendimento de carcaça e peso dos órgãos digestivos.

\section{MATERIAL E MÉTODOS}

Foram utilizados 900 pintos machos de um dia, da linhagem Ross-308, os quais foram alojados ao acaso em galpão convencional, dividido em boxes para 30 aves. Os equipamentos e o manejo foram semelhantes aos utilizados na exploração comercial de frangos. O período de criação foi de 1 a 47 dias de idade. A água e a ração foram fornecidas ad libitum. O programa de luz utilizado foi o seguinte: de 1 a 14 dias, 24 horas de luz (24L:0E); de 15 a 21 dias, luz natural; de 22 a 28 dias, 14L:10E; de 29 a 35 dias, 18L:6E; e de 36 a 47 dias 24L: 0E.

Foram utilizados três tipos de ração de acordo com as fases de criação: inicial (1 a 21 dias), crescimento ( 22 a 42 dias) e acabamento ( 43 a 47 dias). A composição das rações e seus valores nutricionais calculados encontram-se na Tab. 1. Os tratamentos definidos pela forma física e granulometria das rações foram: A- ração farelada com granulometria média; B - ração farelada com granulometria grossa; C - ração granulada com granulometria média; D - ração granulada com granulometria grossa; E - ração expandida-granulada com granulometria média; F - ração expandida-granulada comgranulometria grossa.

Tabela 1. Composição percentual e valores nutricionais calculados das rações para frangos de corte

\begin{tabular}{|c|c|c|c|}
\hline \multirow{2}{*}{ Ingrediente } & \multicolumn{3}{|c|}{ Ração } \\
\hline & Inicial & Crescimento & Acabamento \\
\hline Milho & 59,160 & 64,387 & 69,884 \\
\hline Farelo de soja (46\%) & 31,720 & 26,994 & 22,086 \\
\hline Farinha de carne e ossos $(40 \%)$ & 5,690 & 4,847 & 4,611 \\
\hline Óleo de soja & 1,420 & 1,554 & 1,388 \\
\hline Calcário(39\%) & 0,874 & 1,035 & 1,001 \\
\hline Sal & 0,362 & 0,359 & 0,370 \\
\hline DL-Metionina (99\%) & 0,192 & 0,206 & 0,154 \\
\hline L-Lisina & 0,082 & 0,118 & 0,005 \\
\hline Premix vitaminico-mineral $^{1}$ & 0,500 & 0,500 & 0,500 \\
\hline Total & 100,000 & 100,000 & 100,000 \\
\hline \multicolumn{4}{|l|}{ Nível nutricional $^{2}$} \\
\hline Proteína bruta, \% & 22,00 & 20,00 & 18,00 \\
\hline Energia metabolizável (kcal/kg) & 2980 & 3050 & 3100 \\
\hline Cálcio, \% & 0,980 & 0,950 & 0,900 \\
\hline Sódio, \% & 0,230 & 0,220 & 0,220 \\
\hline Fósforo disponível, \% & 0,480 & 0,420 & 0,400 \\
\hline Metionina, $\%$ & 0,525 & 0,512 & 0,437 \\
\hline Metionina + Cistina, $\%$ & 0,900 & 0,860 & 0,760 \\
\hline Lisina, $\%$ & 1,230 & 1,120 & 0,900 \\
\hline Treonina, $\%$ & 0,825 & 0,748 & 0,676 \\
\hline Triptofano, $\%$ & 0,259 & 0,229 & 0,199 \\
\hline \multicolumn{4}{|c|}{$\begin{array}{l}{ }^{1} \text { Composição do premix: vitamina A } 1.333 .000 \mathrm{UI} \text {, vitamina } \mathrm{D}_{3} 166.700 \mathrm{UI} \text {, vitamina E } 1.667 \mathrm{UI} \text {, ácido fólico } 36 \mathrm{mg} \text {, ácido } \\
\text { pantotênico } 2.837 \mathrm{mg} \text {, ácido nicotínico } 4.000 \mathrm{mg} \text {, biotina } 3,34 \mathrm{mg} \text {, vitamina B6 (piridoxina) } 60 \mathrm{mg} \text {, vitamina B2 (riboflavina) } 459 \mathrm{mg} \text {, } \\
\text { vitamina B1 (tiamina) } 80 \mathrm{mg} \text {, vitamina } \mathrm{B}_{12} 3.333 \mathrm{mcg} \text {, vitamina C } 8.225 \mathrm{mg} \text {, vitamina } \mathrm{K}_{3} 353 \mathrm{mg} \text {, ferro } 20.070 \mathrm{mg} \text {, cobre } 1.904 \mathrm{mg} \text {, } \\
\text { manganês } 3.700 \mathrm{mg} \text {, zinco } 16.464 \mathrm{mg} \text {, iodo } 85 \mathrm{mg} \text {, selênio } 24 \mathrm{mg} \text {, colina } 21,67 \mathrm{~g} \text {, antioxidante } 25 \mathrm{~g} \text {, olaquindox } 12,50 \mathrm{~g} \text {, virginiamicina } \\
3,33 \mathrm{~g} \text {, veículo QSP } 1.000 \mathrm{~g} \text {. } \\
{ }^{2} \text { Calculados segundo Rostagno (2000). }\end{array}$} \\
\hline
\end{tabular}


As rações iniciais granulada e expandidagranuladas foram trituradas após serem granuladas. As granulometrias média e grossa foram obtidas pelo uso de duas peneiras com diâmetro do furo de 3,18 e $4,76 \mathrm{~mm}$, respectivamente, durante a moagem conjunta dos ingredientes. As rações foram submetidas ao teste de granulometria para determinar a distribuição do tamanho de partículas e o cálculo do diâmetro geométrico médio (DGM) (Zanotto, Bellaver, 1996) (Tab. 2). O DGM das rações iniciais foi determinado após a passagem pelo triturador. Os DGM das rações de crescimento e acabamento granuladas e expandida-granuladas, foram semelhantes ao das rações fareladas (antes de serem processadas), variando no produto final o tipo de processamento e sua forma física.

Tabela 2. Diâmetro geométrico médio $(\mathrm{mm})$ das partículas das rações para frangos de corte de acordo com os tratamentos

\begin{tabular}{lcccc}
\hline Forma física & Granulometria & Inicial & Crescimento & Acabamento \\
Farelada & Média & 0,84 & 0,82 & 0,85 \\
& Grossa & 0,88 & 0,86 & 0,88 \\
Granulada & Média & 0,86 & $4,76^{*}$ & $4,76^{*}$ \\
& Grossa & 0,89 & 4,76 & 4,76 \\
\multirow{2}{*}{ Expandida } & Média & 0,94 & 4,76 & 4,76 \\
& Grossa & 0,93 & 4,76 & 4,76 \\
\hline
\end{tabular}

*O tamanho do pelete das rações granulada e expandida-granulada de crescimento e acabamento com granulometria média e grossa foi previamente estabelecido, de $4,76 \mathrm{~mm}$.

Ao final do experimento, 47 dias de idade, todas as aves foram pesadas. $\mathrm{O}$ cálculo da conversão alimentar foi feito com base no consumo médio de ração e no peso médio das aves ao término do período de criação, descontando-se o seu peso inicial. $\mathrm{O}$ número de aves mortas foi registrado diariamente para se fazer o cálculo da porcentagem de viabilidade.

Também aos 47 dias de idade foram sacrificadas cinco aves de cada tratamento para a determinação do rendimento de carcaça e dos pesos do proventrículo, moela, intestinos, fígado e pâncreas. Para o rendimento de carcaça considerou-se o peso do frango sem os pés e a cabeça, expresso como porcentagem do peso vivo. Os órgãos digestivos foram pesados individualmente e expressos como porcentagem do peso vivo.

$\mathrm{O}$ delineamento experimental foi inteiramente ao acaso em um arranjo fatorial de $3 \times 2$ (três formas fisicas e duas granulometrias) e cinco repetições de 30 aves cada, para os dados de desempenho e cinco repetições de uma ave cada para os dados de rendimento de carcaça e porcentagem de peso dos órgãos digestivos em relação ao peso vivo. Os dados foram submetidos à análise de variância e as diferenças entre médias avaliadas pelo teste de Student-Newman-Keuls (User's..., 1985).

\section{RESULTADOS E DISCUSSÃO}

Observou-se efeito da interação forma física e granulometria sobre o desempenho dos frangos (Tab. 3). Nas rações com granulometria média houve aumento significativo do peso à medida que as rações sofreram maior grau de processamento (expandida-granulada > granulada $>$ farelada). Entretanto, com as rações de granulometria grossa, o ganho de peso foi menor com a ração farelada, e não foram observadas diferenças significativas entre as rações granulada e expandida-granuladas. As rações granuladas apresentaram melhor resposta quando foram processadas a partir dos alimentos com granulometria média. Esse fato foi também observado por López e Baião (2002) quando usaram dietas granuladas com granulometria fina. Essa resposta não foi observada quando se utilizaram rações com granulometria mais grosseira. Engberg et al. (2002) também observaram maior peso corporal nas aves alimentadas com dieta granulada, atribuído ao maior consumo e à melhor utilização do alimento. Smith (1995) observou maior ganho de peso em frangos alimentados com ração expandida-granulada em relação àqueles que receberam ração granulada. Em geral, as rações 
com maior grau de processamento melhoraram o ganho de peso das aves.

Tabela 3. Desempenho de frangos aos 47 dias de idade, de acordo com a forma física e a granulometria da ração

\begin{tabular}{|c|c|c|c|c|}
\hline \multirow{2}{*}{ Variável } & \multirow{2}{*}{$\begin{array}{l}\text { Forma } \\
\text { fisica }\end{array}$} & \multicolumn{2}{|c|}{ Granulometria } & \multirow{2}{*}{$\begin{array}{l}\mathrm{CV} \\
(\%)\end{array}$} \\
\hline & & Média & Grossa & \\
\hline \multirow{3}{*}{$\begin{array}{l}\text { Peso corporal } \\
(\mathrm{kg})\end{array}$} & Farelada & $3,040 \mathrm{C}$ & & 1,83 \\
\hline & Granulada & $3,255 \mathrm{~B}$ & $3,276 \mathrm{~A}$ & \\
\hline & Expandida & $3,354 \mathrm{~A}$ & $3,329 \mathrm{~A}$ & \\
\hline \multirow{3}{*}{$\begin{array}{l}\text { Consumo de } \\
\text { ração }(\mathrm{kg})\end{array}$} & Fare & $5,484 \mathrm{~B}$ & $5,509 \mathrm{~B}$ & 1,79 \\
\hline & Granulada & $5,870 \mathrm{~A}$ & $5,879 \mathrm{~A}$ & \\
\hline & Expandida & $5,948 \mathrm{~A}$ & $5,913 \mathrm{~A}$ & \\
\hline \multirow{3}{*}{$\begin{array}{l}\text { Conversão } \\
\text { alimentar (kg:kg) }\end{array}$} & Farelada & $1,831 \mathrm{~A}$ & & 1,39 \\
\hline & Granulada & $1,828 \mathrm{AB}$ & $1,819 \mathrm{~A}$ & \\
\hline & Expandida & 1,797B & $1,800 \mathrm{~A}$ & \\
\hline \multirow{3}{*}{$\begin{array}{l}\text { Viabilidade } \\
(\%)\end{array}$} & Farel & $99,3 \mathrm{~A}$ & $98,7 \mathrm{~A}$ & 2,75 \\
\hline & & $96,7 \mathrm{AB}$ & $98,0 \mathrm{~A}$ & \\
\hline & Expandid & $95,3 \mathrm{~B}$ & $98,0 \mathrm{~A}$ & \\
\hline
\end{tabular}

Médias seguidas de letras distintas na coluna diferem entre si $(\mathrm{P}<0,05)$ pelo teste de SNK.

O consumo de ração não foi influenciado pela granulometria das rações (Tab. 3). Estes resultados diferem dos encontrados por Nir et al. (1994) e López e Baião (2002), os quais observaram que os frangos alimentados com rações de granulometria grossa consumiam mais do que aqueles que recebiam as rações de granulometria fina. Considerando que o DGM das partículas (pós moagem e antes do processamento) foi semelhante para todos os tratamentos (Tab. 2), essa resposta parece lógica.

A forma física da ração teve efeito sobre o consumo $(\mathrm{P}<0,05)$. As aves que consumiram as rações granuladas e expandida-granuladas apresentaram maior consumo em relação àquelas que receberam as rações fareladas. $\mathrm{O}$ maior consumo das granuladas em relação às fareladas pode ser atribuída à maior densidade das rações granuladas, ao tamanho uniforme das partículas e ao impedimento da apreensão seletiva do alimento (Nir et al., 1995; Capdevila,1997).

Para a conversão alimentar observou-se efeito da interação $(\mathrm{P}<0,05)$ granulometria e forma física da ração. As aves que receberam a ração farelada com granulometria média apresentaram pior conversão alimentar em relação aos frangos que receberam a ração expandida-granulada com a mesma granulometria; para a granulometria grossa esse comportamento não foi observado. Isso confirma que o processo de granulação supera os efeitos negativos da menor utilização do alimento quando os frangos são alimentados com rações de granulometria fina (López 1999). Além disso, quando os peletes são produzidos a partir de partículas grosseiras, a degradação das partículas no intestino delgado pode ser demorada, aumentando o peristaltismo e melhorando a digestão do alimento (Nir et al., 1995). Nesse sentido, são aditivos os efeitos da granulometria dos alimentos e da granulação da ração sobre a ingestão de alimento, o ganho de peso e a conversão alimentar (Nir, 1998).

Quanto à viabilidade, observou-se efeito da interação $(\mathrm{P}<0,05)$ granulometria e forma física das rações. As aves alimentadas com a ração expandida-granulada com granulometria média apresentaram menor taxa de viabilidade do que as alimentadas com a ração farelada, enquanto que a viabilidade das aves que receberam as rações de granulometria grossa não foi influenciada pela forma física. Estes resultados estão de acordo com Smith et al. (1995), os quais observaram menor taxa de viabilidade quando os frangos receberam dieta expandida-granulada ao invés de ração somente granulada. Efeitos semelhantes também foram obtidos por Nir et al. (1995), os quais observaram maior taxa de mortalidade dos frangos (machos) quando usaram dieta granulada em relação à farelada. A elevada taxa de mortalidade das aves que receberam a ração expandida-granulada com granulometria média pode ser atribuída ao reduzido número de refeições, que resultou em maior carga intestinal associada com taxa mais rápida do trânsito do alimento e maior quantidade de quimo no intestino, o que aumenta as necessidades de oxigênio no intestino delgado, provocando ascite e síndrome da morte súbita (Nir, 1998).

Os resultados de rendimento de carcaça e porcentagem dos órgãos digestivos em relação ao peso vivo são apresentados na Tab. 4. Para o rendimento de carcaça foi observada interação forma física e granulometria das rações $(\mathrm{P}<0,05)$. 
Efeitos do tamanho da partícula...

Tabela 4. Rendimento de carcaça e peso dos órgãos digestivos de acordo com os tratamentos, expressos como porcentagem do peso vivo

\begin{tabular}{lcccc}
\hline \multirow{2}{*}{ Característica } & & \multicolumn{2}{c}{ Granulometria } & \multirow{2}{*}{ CV (\%) } \\
\cline { 2 - 3 } Rendimento de & Forma física & Média & Grossa & 1,72 \\
carcaça & Farelada & $81,52 \mathrm{Aa}$ & $81,90 \mathrm{Aa}$ & \\
& Granulada & $82,62 \mathrm{Aa}$ & $80,34 \mathrm{Ab}$ & \\
Intestinos & Expandida & $81,44 \mathrm{Aa}$ & $80,64 \mathrm{Aa}$ & \\
& Farelada & $3,21 \mathrm{Aa}$ & $2,76 \mathrm{Ba}$ & 13,98 \\
& Granulada & $2,90 \mathrm{Aa}$ & $3,68 \mathrm{Ab}$ & \\
Moela & Expandida & $2,97 \mathrm{Aa}$ & $3,09 \mathrm{Ba}$ & \multirow{2}{*}{14,46} \\
& Farelada & $1,20 \mathrm{~A}$ & $1,24 \mathrm{~A}$ & \\
& Granulada & $1,03 \mathrm{AB}$ & $0,96 \mathrm{~B}$ & \\
Fígado & Expandida & $0,99 \mathrm{~B}$ & $0,92 \mathrm{~B}$ & \\
& Farelada & $1,58 \mathrm{~B}$ & $1,69 \mathrm{~A}$ & \\
& Granulada & $1,65 \mathrm{AB}$ & $1,76 \mathrm{~A}$ & \\
Pâncreas & Expandida & $1,78 \mathrm{~A}$ & $1,84 \mathrm{~A}$ & 17,17 \\
& Farelada & $0,13 \mathrm{Aa}$ & $0,17 \mathrm{Ab}$ & \\
\hline
\end{tabular}

$\overline{\text { Médias seguidas de letras minúsculas distintas na linha e letras maiúsculas distintas na coluna diferem entre } s i(\mathrm{P}<0,05) \text { pelo teste }}$ SNK.

O rendimento de carcaça das aves alimentadas com a ração granulada com granulometria grossa foi menor do que aquele obtido com as aves que receberam a dieta granulada com granulometria média. Esse comportamento provavelmente se deve à diferença de peso vivo observada nos frangos que foram abatidos $(3,325 \mathrm{~kg}$ granulometria média $v s 3,251 \mathrm{~kg}$ - granulometria grossa). Como as amostras das aves para o abate foram tomadas ao acaso, essa diferença foi superior à observada nos resultados de desempenho (Tab. 3). De acordo com López e Baião (2002), não há diferenças no rendimento carcaça de frangos alimentados com dietas fareladas e granuladas com diferentes granulometrias.

Os dados referentes ao peso dos órgãos digestivos são apresentados na Tab. 4. As aves alimentadas com as rações granuladas com granulometria grossa apresentaram maior peso dos intestinos em relação àquelas que receberam as rações granuladas e expandidas-granuladas com a mesma granulometria e também em relação àquelas que consumiram as rações granuladas com granulometria média. Essa resposta pode estar relacionada com o menor rendimento de carcaça observado nesse grupo de frangos e, por conseguinte, com maior peso do trato gastrintestinal. Não foram observadas diferenças entre as rações fareladas $\mathrm{e}$ expandidas-granuladas quanto ao peso dos intestinos. Choi et al. (1986) verificaram maior peso do trato gastrintestinal em frangos com oito semanas de idade alimentados com dietas fareladas em relação àqueles alimentados com dietas granuladas.

Os frangos alimentadas com a ração granulada com granulometria média apresentaram pesos da moela semelhantes ao daqueles que receberam as dietas fareladas e expandida-granuladas com a mesma granulometria. Para as aves alimentadas com as rações com granulometria grossa o mesmo comportamento não foi observado, isto é, as alimentadas com a ração farelada apresentaram maior peso da moela do que as aves que receberam as rações processadas. Estes resultados estão de acordo com os encontrados por Nir et al. (1995), os quais observaram menor peso da moela nos frangos que receberam rações granuladas quando comparados aos que receberam as fareladas. Engberg et al. (2002) também mostraram que aves alimentadas com dietas granuladas apresentaram menor peso da moela em relação às aves que receberam dietas fareladas. Este fato é atribuído à maior taxa de passagem das rações granuladas, o que provocaria menor volume de alimento na moela e, conseqüentemente, menor atividade dos músculos (Macari et al., 1994; López, Baião, 2002). 
Para o peso do pâncreas foi observado efeito da interação forma física e granulometria das rações $(\mathrm{P}<0,05)$. As aves alimentadas com as rações fareladas com granulometria grossa apresentaram maior peso do pâncreas em relação às que receberam as rações fareladas com granulometria média. Esse efeito não foi observado nas rações processadas. Estes resultados estão de acordo com Engberg et al. (2002), os quais observaram em rações fareladas maior peso do pâncreas nas aves alimentadas com granulometria grossa em relação às que receberam ração com granulometria média.

Nas rações com granulometria grossa, o peso do pâncreas foi maior na dieta oferecida na forma de farelo. Nir et al. (1995) não observaram efeito da forma física das rações em frangos de corte com 40 dias de idade e Engberg et al. (2002) encontraram menor peso do pâncreas em aves alimentadas com dietas granuladas.

Observou-se diferença de peso do fígado somente entre as rações farelada e expandidagranulada com granulometria média. Nas rações com granulometria grossa os pesos foram semelhantes.

De acordo com os resultados encontrados neste experimento pode-se concluir que: para rações fareladas a granulometria mais grosseira dos ingredientes é a mais indicada e para rações granuladas e/ou expandidas pode-se usar granulometria média ou grossa.

\section{REFERÊNCIAS BIBLIOGRÁFICAS}

CAPDEVILA, J. Efectos de la granulación sobre la formulación de raciones en avicultura. Sel. Avícola, v.39, p.465-474, 1997.

CHOI, J.H.; SO, B.S.; RYU, K.S. et al. Effects of pelleted or crumbled diets on the performance and the development of the digestive organs of broilers. Poult. Sci., v.65, p.594-597, 1986.

DEATON, J.W.; LOTT, B.D.; BRANTON, S.L. Corn grind size and broilers reared under two temperature conditions. J. Appl. Poult. Sci., v.4, p.402-406, 1995.

ENGBERG, R. M.; HEDEMANN, M. S.; JENSEN, B. B. The influence of grinding and pelleting of feed on the microbial composition and activity in the digestive tract of broiler chickens. Br. Poult. Sci., v.43, p.569-579, 2002.

HEIDENREICH, H.E. Benefícios y efectos secundarios de la expansion. Avic. Profesional, v.17, n.10, p.35-38, 1999.

LOPEZ, C.A.A. Efeitos dos métodos de moagem e da forma física da ração sobre o desempenho, a digestibilidade e composição da carcaça de frangos de corte. 1999. 44f. Dissertação (Mestrado em Zootecnia) - Escola de Veterinária, Universidade Federal de Minas Gerais, Belo Horizonte.

LOPEZ, C.A.A.; BAIÃO, N.C. Efeitos da moagem dos ingredientes e da forma física da ração sobre o desempenho de frangos de corte. Arq. Bras. Med. Vet. Zootec., v.54, p.189-195, 2002.

LOTT, B.D.; DAY, E.J.; DEATON, J.W. et al. The effect of temperature, dietary energy level and corn particle size on broiler performance. Poult. Sci., v.71, p.618-624, 1992.

LUCHT, W.H. Mejoramiento de la producción de pollo por medio de la expansión de alimento. Ind. Avícola, Outubro, p.32-35, 2002.

MACARI, M.; FURLAN, R.L.; GONZALES, E. Fisiologia aviária aplicada a frangos de corte. Jaboticabal: FUNEP- UNESP, 1994. 296p.

NIR, I. Resposta de frangos de corte à estrutura alimentar: ingestão de alimentos e trato gastrointestinal. In: SIMPÓSIO INTERNACIONAL SOBRE NUTRIÇÃO DE AVES, 1998, Campinas. Anais... Campinas: CBNA, 1998. p. 49-68.

NIR, I.; HILLEL, R.; PTICHI, I. et al. Effect of particle size on performance. 3. Grinding pelleting interactions. Poult. Sci., v.74, p.771783, 1995.

NIR, I.; SHEFET, G.; NITSAN, Z. Effect of grain particle size performance. 2. Grain texture interactions. Poult. Sci., v.73, p.781-791, 1994.

PEISKER, M. Influence of expansion on feed components. Feed Mix, v.2, p.26-31, 1994.

PORTELLA, F.J.; CASTON, L.J.; LEESON, S. Apparent feed particle size preference by broilers. Can. J. Anim. Sci., v.68, p.923-930, 1988.

Arq. Bras. Med. Vet. Zootec., v.56, n.2, p.214-221, 2004 
REECE, F.N.; LOTT, B.D.; DEATON, J.W. The effects of hammer mill screen size on ground corn particle, pellet durability and broiler performance. Poult. Sci., v.65, p.1257-1261, 1986.

ROKEY, G. Tecnologia de la extrusión e implicaciones nutricionales. In: CURSO DE ESPECIALIZACIÓN: Avances en nutrición y alimentación animal, 11., Barcelona, España, FEDNA, 1995. p.270-286.

ROSTAGNO, H.S. Tabelas brasileiras para aves e suínos: composição de alimentos e exigências nutricionais. Viçosa:UFV, Departamento de Zootecnia, 2000. p.141.
SMITH, P.A.; FIRMAN, J.D.; DALE, N.M. Effects of feed processed in an annular gap expander on subsequent broiler performance. Poult. Sci., v.74, suppl. 1, p.145, 1995.

USER'S guide: statistics. Cary, NC: SAS Institute, 1985. 956p.

ZANOTTO, L.D.; BELLAVER, C. Método de determinação da granulometria de ingredientes para uso em rações de suínos e aves. Concórdia: EMBRAPA-CNPSA, 1996. 5p. (Comunicado Técnico, Dez/96). 